\title{
Control and Modeling of Electromagnetic Converter Dedicated to Electric Traction
}

\author{
Souhir Tounsi \\ National School of Electronics and Telecommunications of Sfax, Sfax University, ESSE Laboratory, Sfax, Tunisia \\ Email address: \\ souhir.tounsi@enetcom.rnu.tn

\section{To cite this article:} \\ Souhir Tounsi. Control and Modeling of Electromagnetic Converter Dedicated to Electric Traction. International Journal of Electrical \\ Components and Energy Conversion. Vol. 3, No. 4, 2017, pp. 70-82. doi: 10.11648/j.ijecec.20170304.11
}

Received: November 6, 2017; Accepted: December 1, 2017; Published: December 5, 2017

\begin{abstract}
This paper describes a parameterized dynamic model of an electromagnetic converter inserted into a model of the power train of an electric vehicle in the goal to improve its dynamic characteristic. Generally for electromechanical interrupters, the stability of the contact during the closing and opening control is not studied. In this context, this paper presents the dynamic behavior of the interrupter in order to analyze the performances and to improve the dynamic characteristic of the electric vehicles. The parameters can be optimized by genetic algorithms method.
\end{abstract}

Keywords: Electromagnetic Converter, Dynamic Model, Electric Vehicle, Modelling, Simulation, Performances

\section{Introduction}

A determining factor is the choice of components of the electrical systems power train such as electric vehicle regarding its influence in the production cost and the energy consumption of the global system. A basic component in this type of energy conversion chain is the electric converter. Several research studies have shown that the three-phase converter with two voltage level allows to expect good performance for industrial application as the motorization of electric cars [1-4]. Two types of configurations can be presented to knowledge are:

1. Converter with two voltage levels with Insolated Bipolar Transistors (IGBTs) having multiple disadvantages, such as the floating voltage problem of an arm, tail current, energy loss by conduction and switching, need to integrate a cooling system for the majority of cases and presence of capacities: TriggerEmitter, Trigger-Collector and Collector-Emitter especially at high frequencies [1-4].

2. Converter with two voltage levels to electromagnetic switches having several advantages such as mechanical isolation between the power circuit and the control circuit without any of the disadvantages mentioned above for the converter with IGBTs [5-14].

Hence, the choice fell on an innovated structure of electromagnetic converter having the disadvantage of a low switching frequency. Several sizing and modeling studies of this type of converter encouraging its integration at low frequencies electrical systems are developed and presented in the literature [1-5].

In this context, firstly this paper presents the structure and the modeling approach of the electromagnetic converter dedicated to electric vehicles motorization application. Secondly, this paper presents the principle of coupling of this type converter to electric vehicles power chain. To finish with a presentation and descriptions of simulation results completed by a conclusion.

\section{Objectives and Methodology}

The primary the objective of this study is to argue the choice of electromagnetic converter compared to its equivalent with IGBTs to push the multiple disadvantages of the converters with IGBTs already mentioned. An essential advantage of the electromagnetic converters is their reduced cost relating to IGBTs converter.

The design methodology of this converter type is based on the coupling of design and modeling programs of the various components of the electric vehicle power chain. Design problem solving of the power chain takes into account the systemic interactions between the various components. For example the power chain is adapted to operate at low frequency, the outside diameter of the motor is delimited by 
the space reserved for the motor etc. [3-22].

The method chosen for the design of the power chain components is the analytical method view it brings the following benefits:

1. Fast and thereafter consistent with optimizations approaches.

2. It takes into account the interactions between the components and permit to evaluate the performance of the power chain by simple equations.

3. The resolution of an electrical device design problem is direct (without iterations).

4. This method is adjusted and supplemented by the finite elements method [1-22].

\section{Dynamic Model of the Electromagnetic Converter}

\subsection{Structure of Electromagnetic Converter Arm}

An arm of the electromagnetic converter (Figure1) comprise tow left electromagnets and two right electromagnets to increase the switching frequency regardind the movable stem strength is multiplied by two.

When the coils of the electromagnet 1 are energized, the moving stem is attracted until the value of the displacement $\mathrm{D}_{\text {co }}$ related to the opening of the power contacts. In this case the power contact open at repot are closed and the other closed at repot are opened. The duration of opening and closing is imposed by the generator of the supply voltages of the coils and of the dynamics of two electromagnets. Indeed, the displacement of the movable stem may exceed the value $\mathrm{D}_{\text {co, }}$, since the return spring are attached to the yoke of the electromagnet to damp the collusion between the movable stem and the yoke. In this case the amortization springs are compressed. The movement of the movable stem toward the other direction to change the power contacts state is ensured by canceling the coil voltage of the electromagnet 1 (freewheeling phase) and supplyng the coils of the electromagnets 2 to change the sign of the attraction strength of the stem and subsequently the direction of movement of the moving stem [1-12].

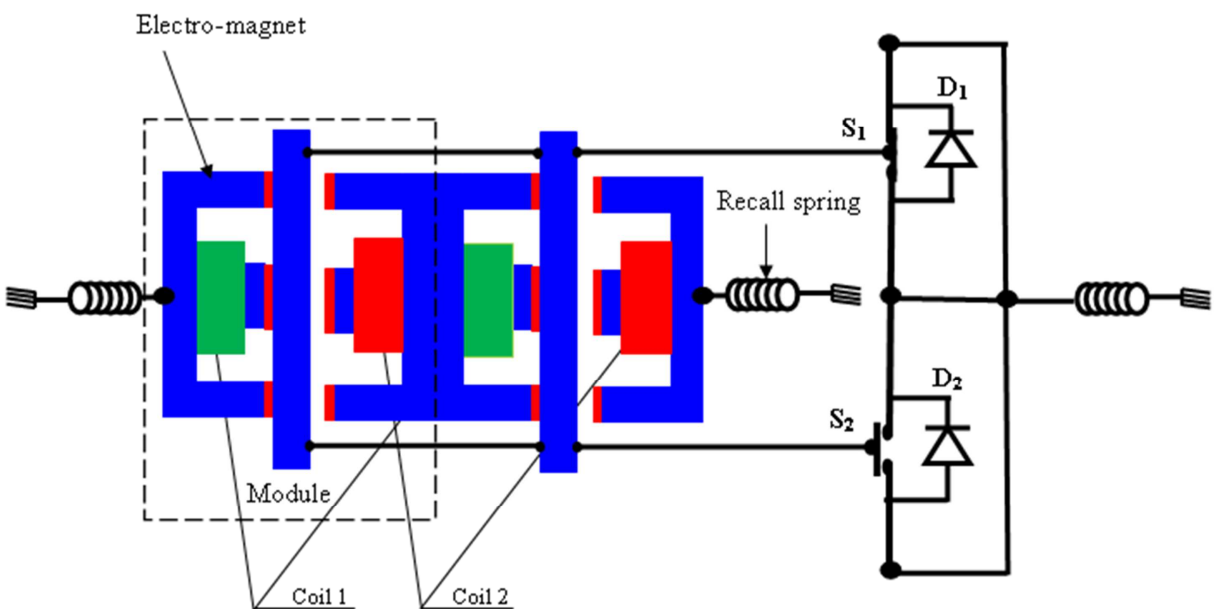

Figure 1. Arm of the electromagnetic converter.

\subsection{Modelling of the Electromagnets Control Circuit}

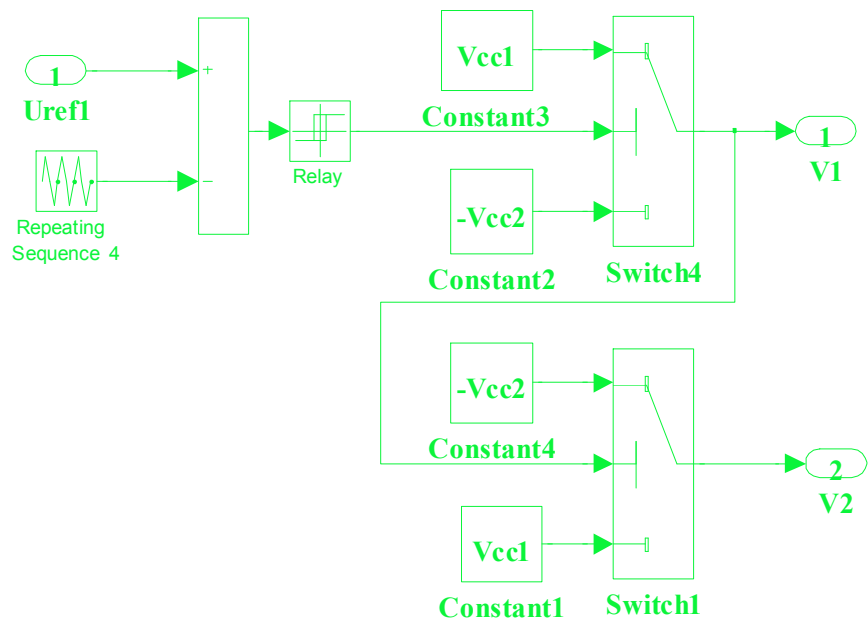

Figure 2. Control circuit model of the electromagnets arm. 
The control circuit model of the an electromagnets arm (Figure 2) is based on the comparison of the reference voltage delivred from the speed and current regulator of the electric vehicles power chain. The comparator output drives a hysteresis varying between 0 and 1 to reproduce the waveform of the control signal 1 . The output of the hyterisis is converted into a voltage varying between the values $+\mathrm{Vcc}$ when the signal is at 1 and $-\mathrm{Vcc}$ when the signal is at zero.
This signal is related to the voltage supplying the coils of the electromagnet 1 (V1). The voltage supplying the coils of the electromagnet 2 (V2) is the inverse of the voltage V1 [1-12].

\subsection{Electromagnents Inductances Modelling}

The design parameters of the electromagnet are shown in Figure 3 [1-12].

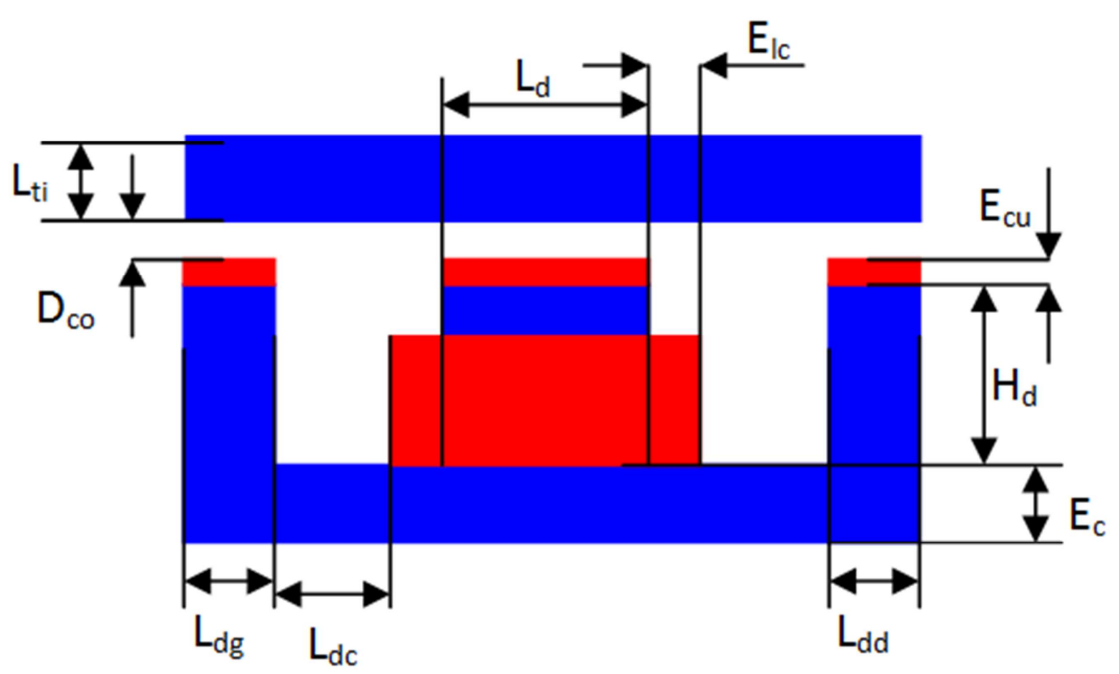

Figure 3. Design parameters of the electromagnet.

The two electromagnets inductances are expressed by the following relations.

$$
L_{1}=\mu_{0} \times N_{s p}^{2} \times\left(\frac{\frac{S_{d}}{2}}{2 \times\left(E_{c u}+D_{c o}-x_{t}\right)}+\frac{H_{c u} \times E_{b}}{E_{l c}+L_{d c}}\right)
$$

$$
L_{2}=\mu_{0} \times N_{s p}^{2} \times\left(\frac{\frac{S_{d}}{2}}{2 \times\left(E_{c u}+x_{t}\right)}+\frac{H_{c u} \times E_{b}}{E_{l c}+L_{d c}}\right)
$$

Where $E_{b}$ is the length of the main tooth (or length of the stem), $\mathrm{H}_{\mathrm{cu}}$ is the height of the coil and $\mathrm{L}_{\mathrm{dc}}$ is the distance between the coil and the right tooth.

The simulink model of the two electromagnets inductance is illustrated in the Figure 4.

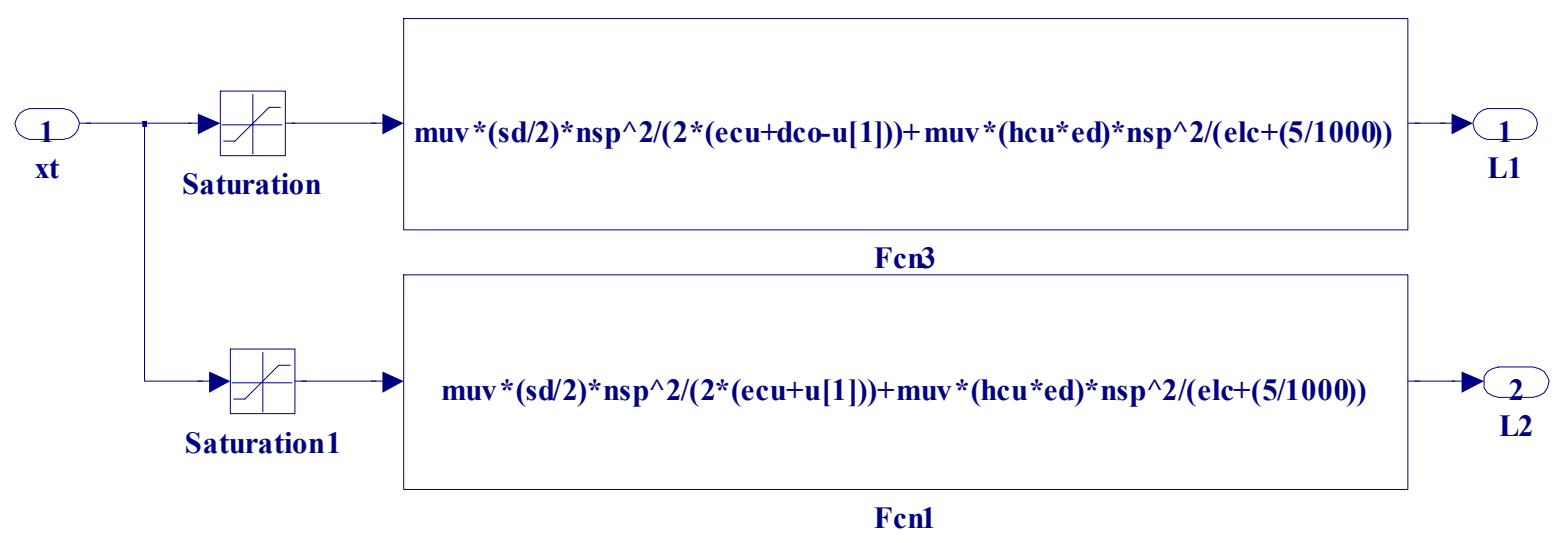

Figure 4. Simulink model of the two electromagnets inductance.

\subsection{Electromagnetic Strengnth Modelling}

The coils phase's voltages are expressed by the following

$$
V_{1}=R \times i_{1}+\frac{d\left(L_{1} \times i_{1}\right)}{d t}
$$
relationships: 


$$
V_{2}=R \times i_{2}+\frac{d\left(L_{2} \times i_{2}\right)}{d t}
$$

where $\mathrm{R}$ is the coil resistance, $\mathrm{L}_{1}$ and $\mathrm{L}_{2}$ are respectively the inductance of the coil 1 and 2 and $i_{1}, i_{2}$ are respectively the current of the coil 1 and 2.

The strength developed by the two electro-magnets is expressed by the following equation:

$$
F_{e m}=\frac{1}{V_{t}} \frac{d\left(\frac{1}{2} \times\left(L_{1} \times i_{1}^{2}+L_{2} \times i_{2}^{2}\right)\right)}{d t}
$$

The electrical-mechanical model of left and right electromagnets is implanted under the simulation environment Matlab-Simulink according to Figure 5.

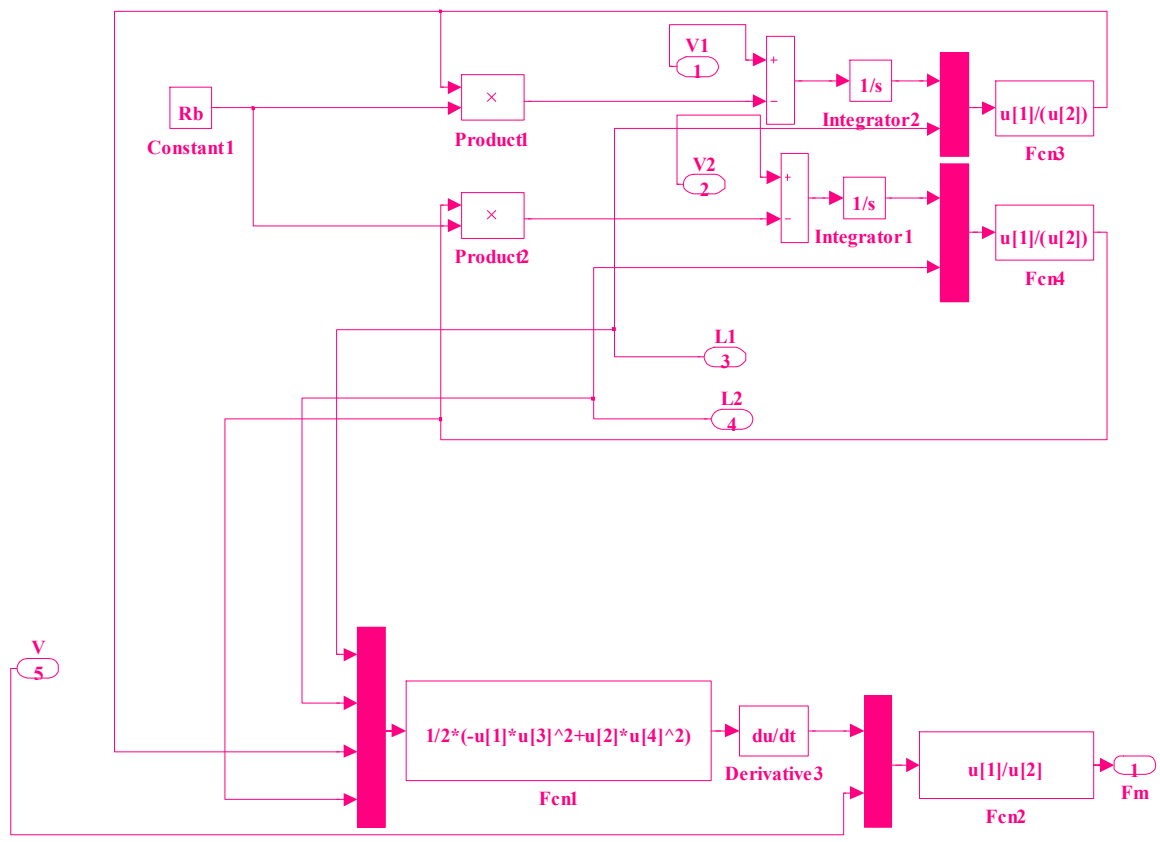

Figure 5. Electrical-mechanical model of left and right electromagnets.

\subsection{Motion Equation of the Movable Stem}

The movable stem motion equation is derived from the fundamental relation of dynamic.

$$
V_{t}=\frac{d x_{t}}{d t}
$$

$$
m_{t} \times \frac{d V_{t}}{d t}=F_{e m}-\left(s+n_{u} \times a b s\left(V_{t}\right)+x_{s i} \times V_{t}^{2}\right)-F_{R}\left(x_{t}\right)
$$

$$
\begin{aligned}
& \text { if } x_{t} \geq D_{c o}, F_{R}\left(x_{t}\right)=k \times\left(x_{t}-D_{d c o}\right) \\
& \text { if } x_{t} \leq 0, F_{R}\left(x_{t}\right)=-k \times a b s\left(x_{t}\right)
\end{aligned}
$$

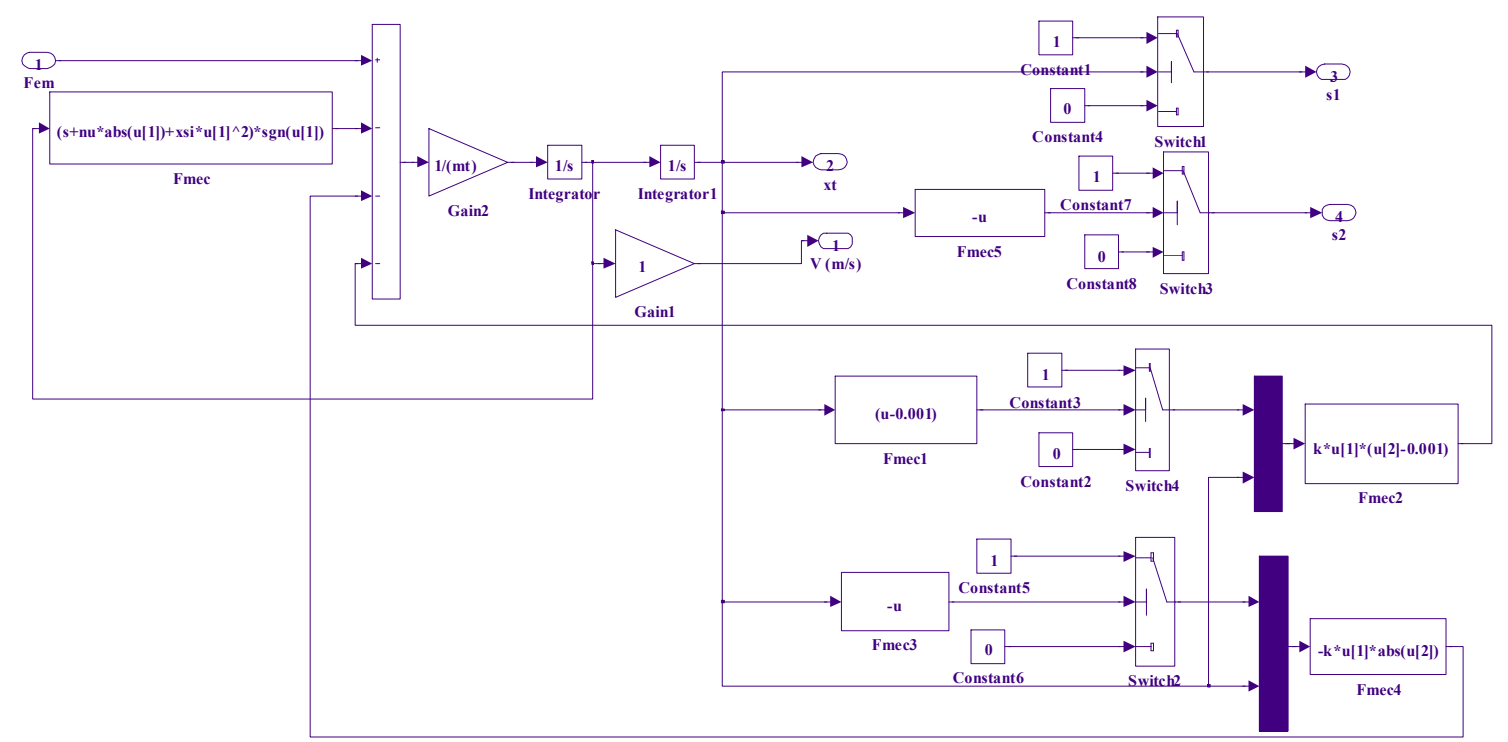

Figure 6. Simulink model of the movable stem dynamic equation. 
where $m_{t}$ is the movable stem mass, $x_{t}$ and $V_{t}$ are respectively the movable stem position and speed, $D_{c o}$ is the power contacts opening, $\mathrm{s}$ is the dry friction coefficient, $\mathrm{n}_{\mathrm{u}}$ is the viscous friction coefficient, $\mathrm{x}_{\mathrm{si}}$ is the fluid friction coefficient, $F_{R}$ is the total resistance strength, $\mathrm{k}$ is stiffness of the spring and $\mathrm{F}_{\mathrm{em}}$ is the movable stem strength.

The movable stem motion equation is implemented under Matlab-Simulink simulation environment according the
Figure 6.

\subsection{Global Model of the Electromagnetic Converter Arm}

The coupling of various sub model of the electromagnetic converter leads to the global model of an arm of the converter (Figure 7) having as an input the reference voltage and as outputs the two control signals of an arm S1 and S2.

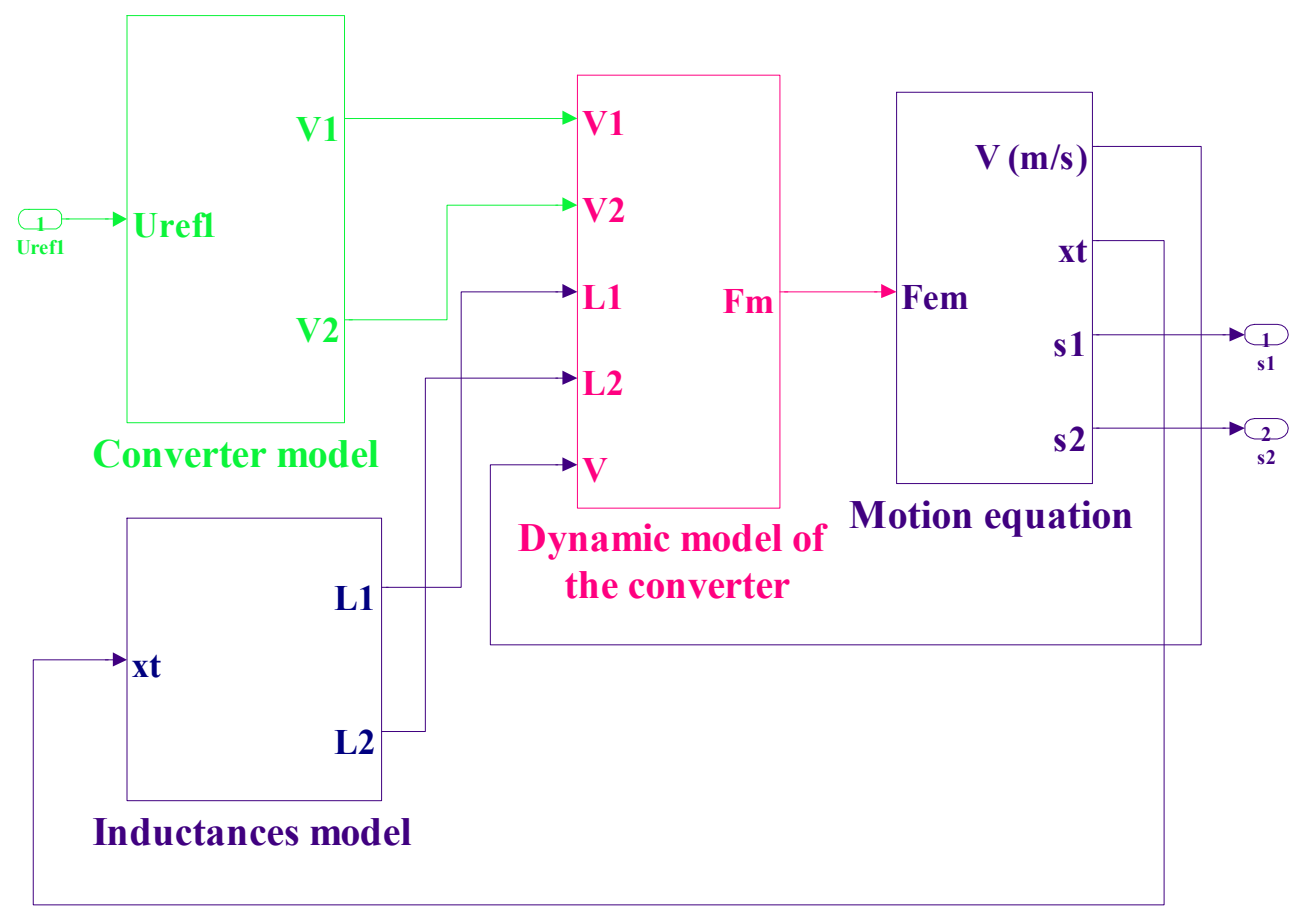

Figure 7. Simulink model of the electromagnetic converter.

\section{Control Model of Electric Vehicles Power Chain with Electromagnetic Converter}

\subsection{Speed and Currents Regulations}

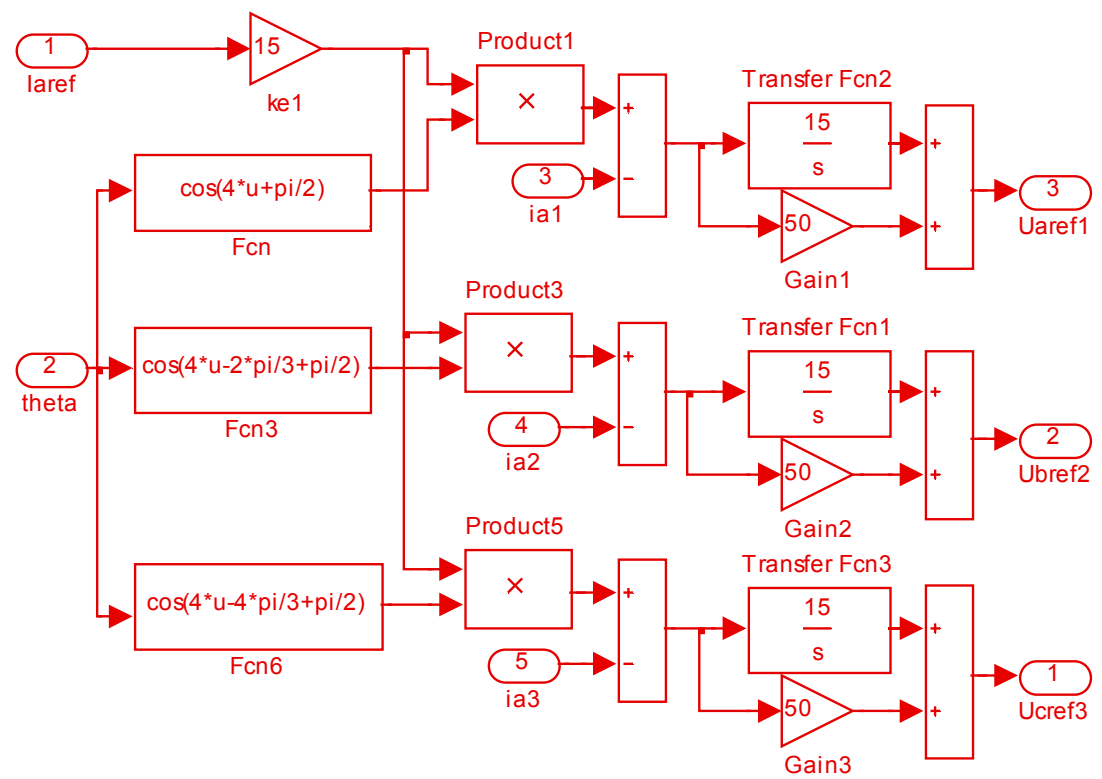

Figure 8. Simulink model of the current regulator. 
The speed regulator generates the amplitude of the reference currents minimizing the error between the reference speed and the response speed. Indeed, the reference speed is compared to the response speed. The comparator output drives a proportional / integral controller type (PI) to provide the amplitude of the reference currents minimizing the speed error.

Regulators currents allow the imposition of currents having the same shape and in phase with the back electromotive forces. Indeed, the reference currents are compared to the phase's current of the motor. The outputs of the three comparators attack three regulators of the type proportional / integral (PI) to provide three reference voltages necessary to impose ideal currents in phase with the back electromotive forces and to minimize the error between the reference speed and the response speed of the electric vehicle [4].

The Simulink model of the current regulator is illustrated in Figure 8:

\subsection{Back Electromotive Forces Model}

The back electromotive forces are expressed by the three following equations [1-6]:

$$
\begin{gathered}
\mathrm{e}_{1}=\frac{2}{3} \times \mathrm{k}_{\mathrm{e}} \times \Omega \times \cos \left(\mathrm{p} \times \Omega \times \mathrm{t}+\frac{\pi}{2}\right) \\
\mathrm{e}_{2}=\frac{2}{3} \times \mathrm{k}_{\mathrm{e}} \times \Omega \times \cos \left(\mathrm{p} \times \Omega \times \mathrm{t}-\frac{2 \times \pi}{3}+\frac{\pi}{2}\right) \\
\mathrm{e}_{3}=\frac{2}{3} \times \mathrm{k}_{\mathrm{e}} \times \Omega \times \cos \left(\mathrm{p} \times \Omega \times \mathrm{t}-\frac{4 \times \pi}{3}+\frac{\pi}{2}\right)
\end{gathered}
$$

where ke is the electric constant of the motor and $\Omega$ is the angular velocity of the motor and $p$ is the number of pole pairs.

These equations are implanted under the Matlab-Simulink environment according to Figure 9:

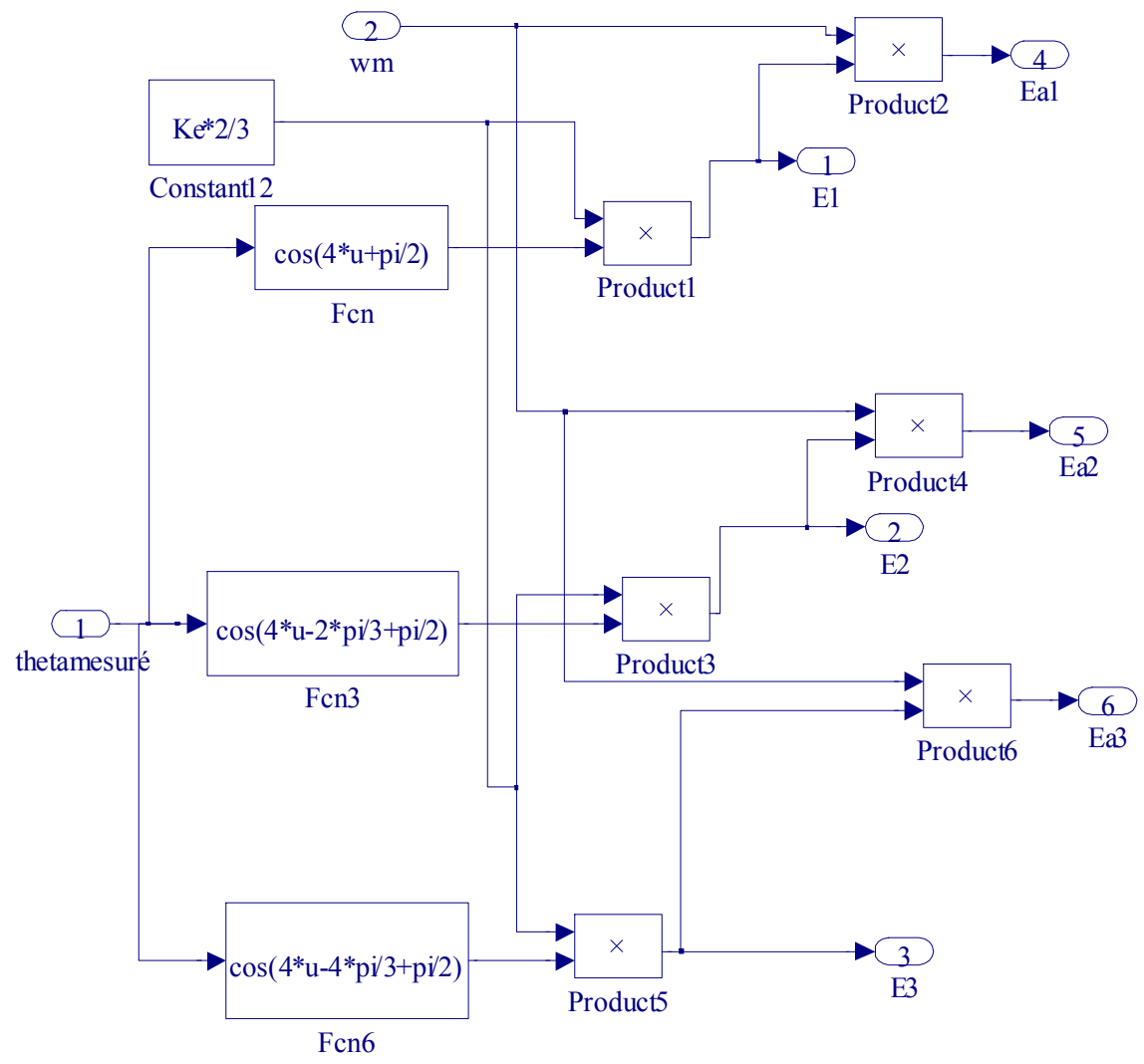

Figure 9. Simulink model of the back electromotive forces.

\subsection{Motion Equation}

The vehicle motion equation is derived from the fundamental relationship of dynamics [1-15]:

$\left(M_{v} \times R_{r}\right) \times \frac{d v}{d t}=r_{d} \times\left(T_{e m}-T_{f}-T_{m e c}\right)-\left(F_{r}+F_{a}+F_{c}\right) \times R_{r}$

Where $F_{r}$ is the rolling resistance force, $\mathrm{Fa}$ is the aerodynamic force, $F_{c}$ is the force of gravity, $r_{d}$ is the amplification ratio, $T_{e m}$ is the electromagnetic torque, $T_{f}$ is the iron losses torque, $T_{\text {mec }}$ is the mechanical losses torque, $R_{r}$ is the radius of the wheel of the car, and $v$ the speed of the car and $\mathrm{M}_{\mathrm{v}}$ and the mass of the car.

The vehicle motion equation is implanted under the environment Matlab / Simulink according to Figure 10 [1-15]. 


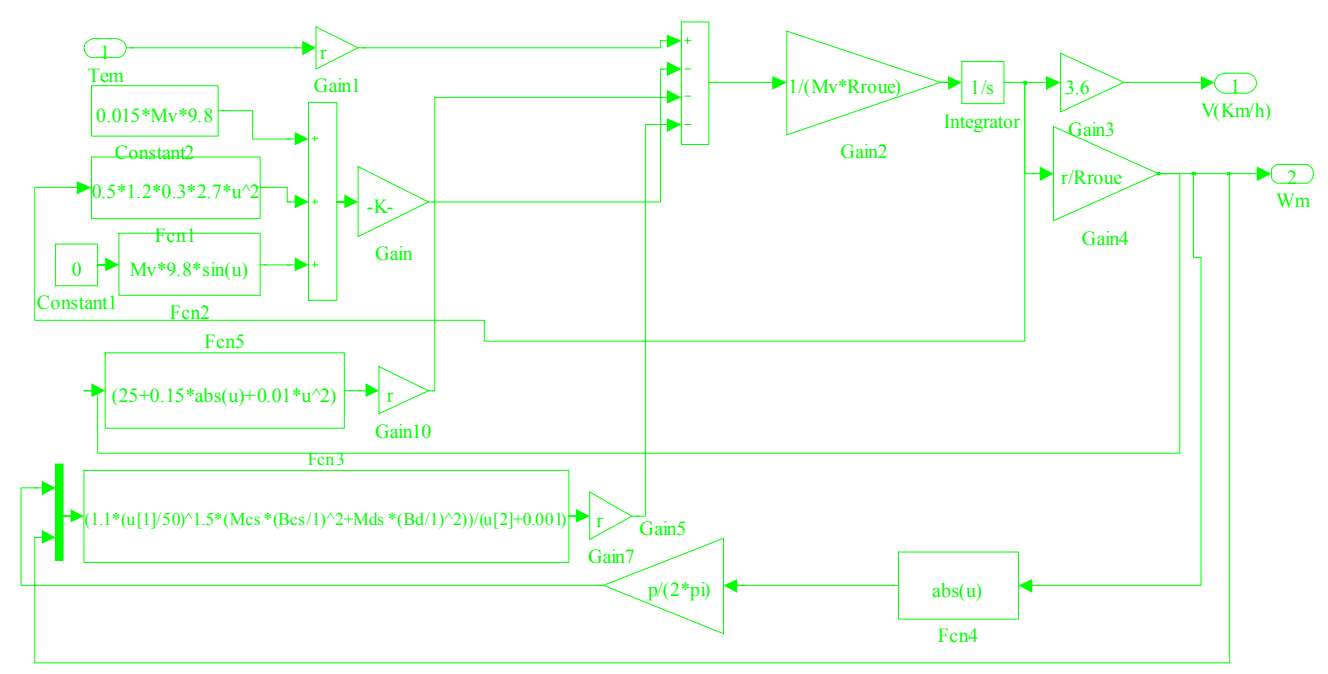

Figure 10. Simulink model of the motion equation.

\subsection{Battery-DC/DC Elevetor Converter-Motor Model}

Regarding the dynamics of the electromagnetic converter, it must be powered by a high voltage equal to 14500 volts. Therefore, the voltage delivered by the batteries is elevated to a value equal to 14500 Volt via a DC-DC elevator converter kept constant by pulse width modulation technique. This voltage is filtered by a super-capacity. The super-capacity also increases the vehicle's autonomy, since it offers additional stored energy.

Each phase of the motor is equivalent to a resistor in series with an inductance and a back electromotive force.

The three phase model of the motor is described by the following equations.

$$
\begin{gathered}
\mathrm{u}_{1}=\mathrm{R} \times \mathrm{i}_{1}+(\mathrm{L}-\mathrm{M}) \times \frac{\mathrm{di_{1 }}}{\mathrm{dt}}+\frac{2}{3} \times \mathrm{k}_{\mathrm{e}} \times \Omega \times \cos (\mathrm{p} \times \Omega \times \\
\left.\mathrm{t}+\frac{\pi}{2}\right)
\end{gathered}
$$

$\mathrm{u}_{2}=\mathrm{R} \times \mathrm{i}_{2}+(\mathrm{L}-\mathrm{M}) \times \frac{\mathrm{di}_{2}}{\mathrm{dt}}+\frac{2}{3} \times \mathrm{k}_{\mathrm{e}} \times \Omega \times \cos (\mathrm{p} \times \Omega \times$
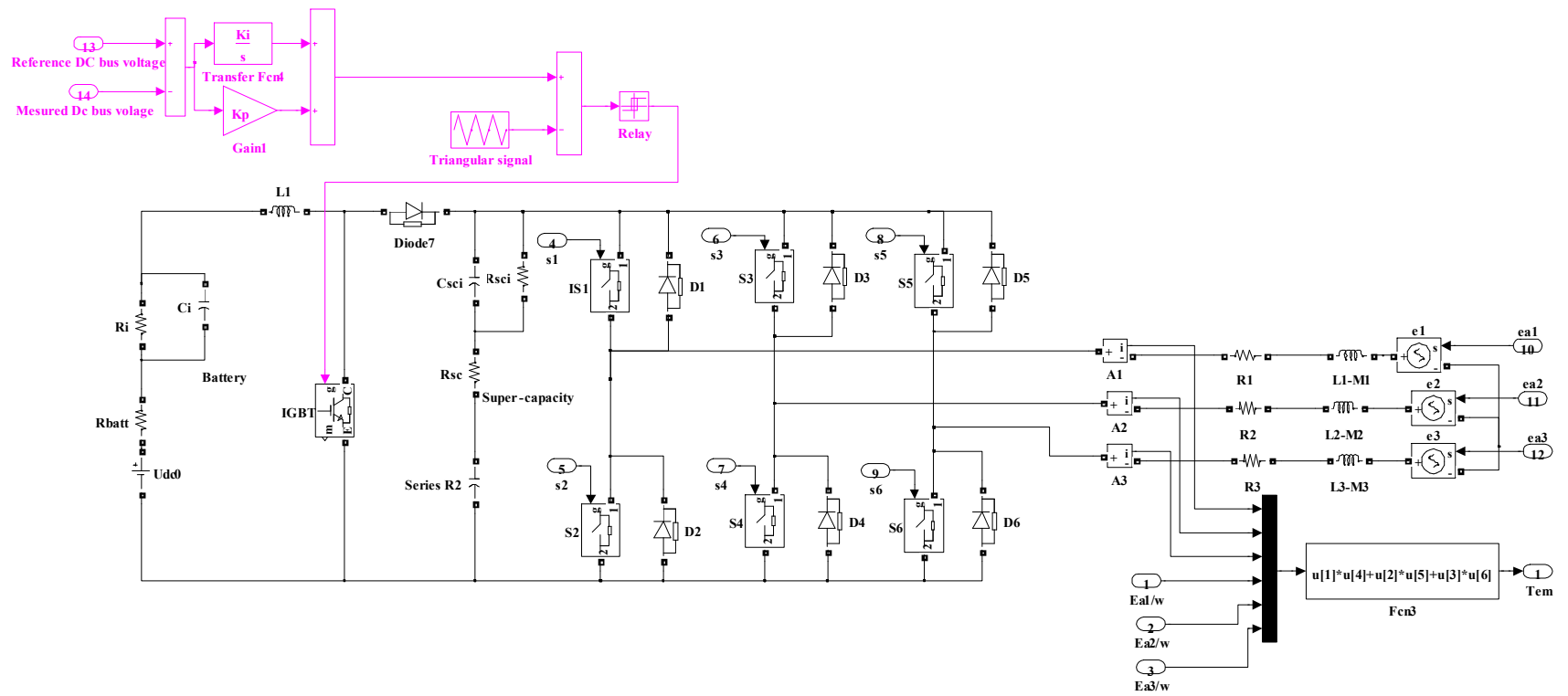

Figure 11. Simulink model of the Battery-DC/DC elevator converter-motor-AC converter.

$$
\begin{gathered}
\mathrm{u}_{3}=\mathrm{R} \times \mathrm{i}_{3}+(\mathrm{L}-\mathrm{M}) \times \frac{\mathrm{di}_{3}}{\mathrm{dt}}+\frac{2}{3} \times \mathrm{k}_{\mathrm{e}} \times \Omega \times \cos (\mathrm{p} \times \Omega \times \\
\left.\mathrm{t}-\frac{4 \times \pi}{3}+\frac{\pi}{2}\right)
\end{gathered}
$$

where $\mathrm{R}, \mathrm{L}, \mathrm{M}$ and $\mathrm{k}_{\mathrm{e}}$ are respectively the resistance, inductance, and mutual inductance and the electric motor constant, $\mathrm{i}_{\mathrm{i}}$ and $\mathrm{u}_{\mathrm{i}}$ are the current and the voltage of the phase i.

The electromagnetic torque is given by the following relationship:

$$
\mathrm{T}_{\mathrm{em}}=\frac{1}{\Omega}\left(\mathrm{e}_{1} \times \mathrm{i}_{1}+\mathrm{e}_{2} \times \mathrm{i}_{2}+\mathrm{e}_{3} \times \mathrm{i}_{3}\right)
$$

where ei is the electromotive force against the i phase.

The model of the Battery-DC/DC elevator convertermotor-AC converter is implanted under the Matlab-Simulink according to Figure 11: 


\subsection{Power Chain Global Model}

The control model is based on the scalar control with compensation of the electromotive forces. Four control loops are used to minimize the error between the reference speed and the speed of response and impose phase currents in phase with the back electromotive forces to minimize consumption.
The first control loop enables to provide the amplitude of the reference current and the other three control loops allow the imposition of the phase currents in phase with the back electromotive forces and having a sinusoidal shape. This model is implanted under the simulation environment Matlab-Simulink accordind to the Figure 12 [1].

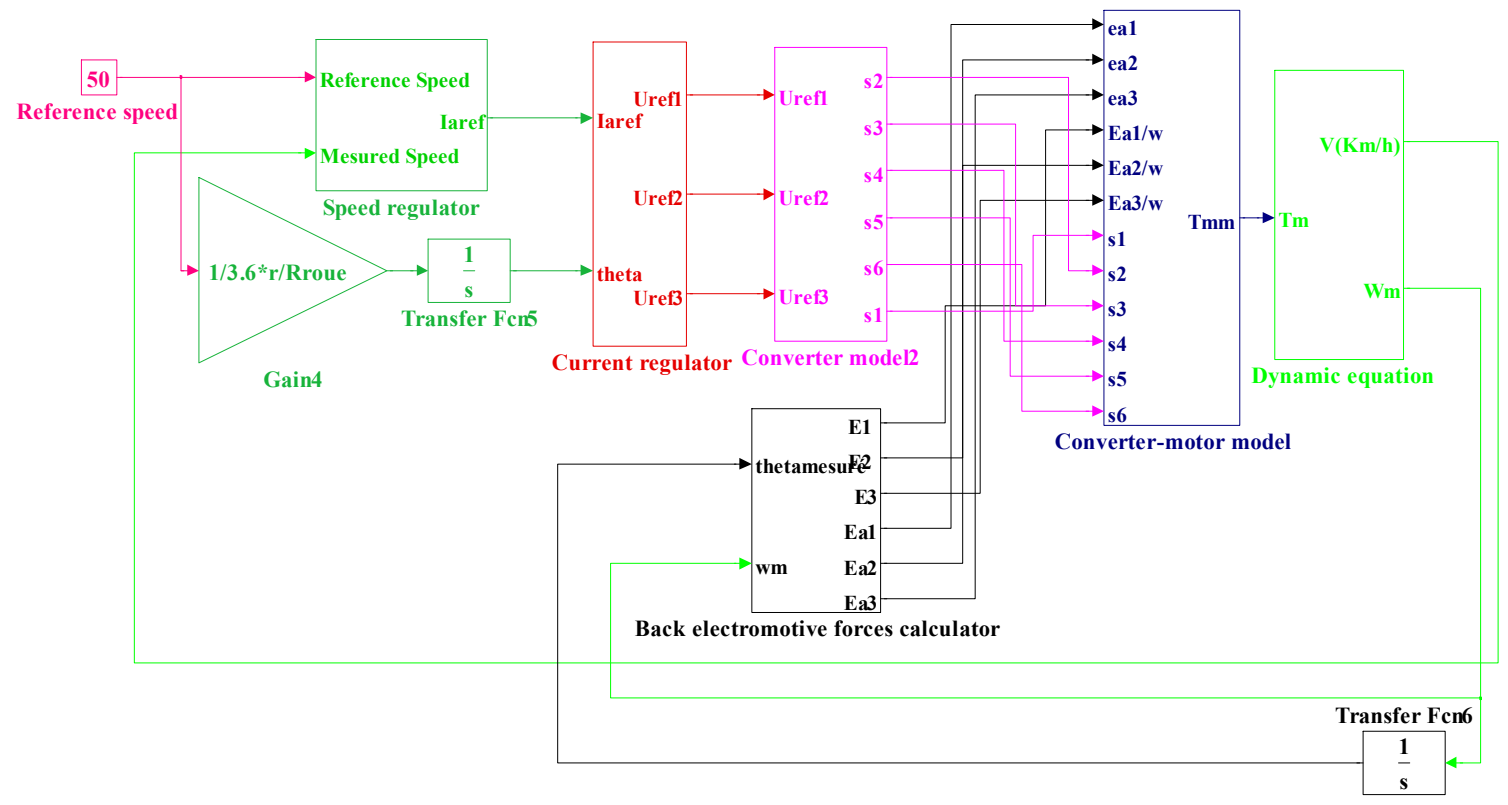

Figure 12. Simulink model of the global power chain with electromagnetic converter.

\section{Simulations Results and Discussion}

The battery voltage and the DC bus elevated volatge are illustrated in Figure 13.
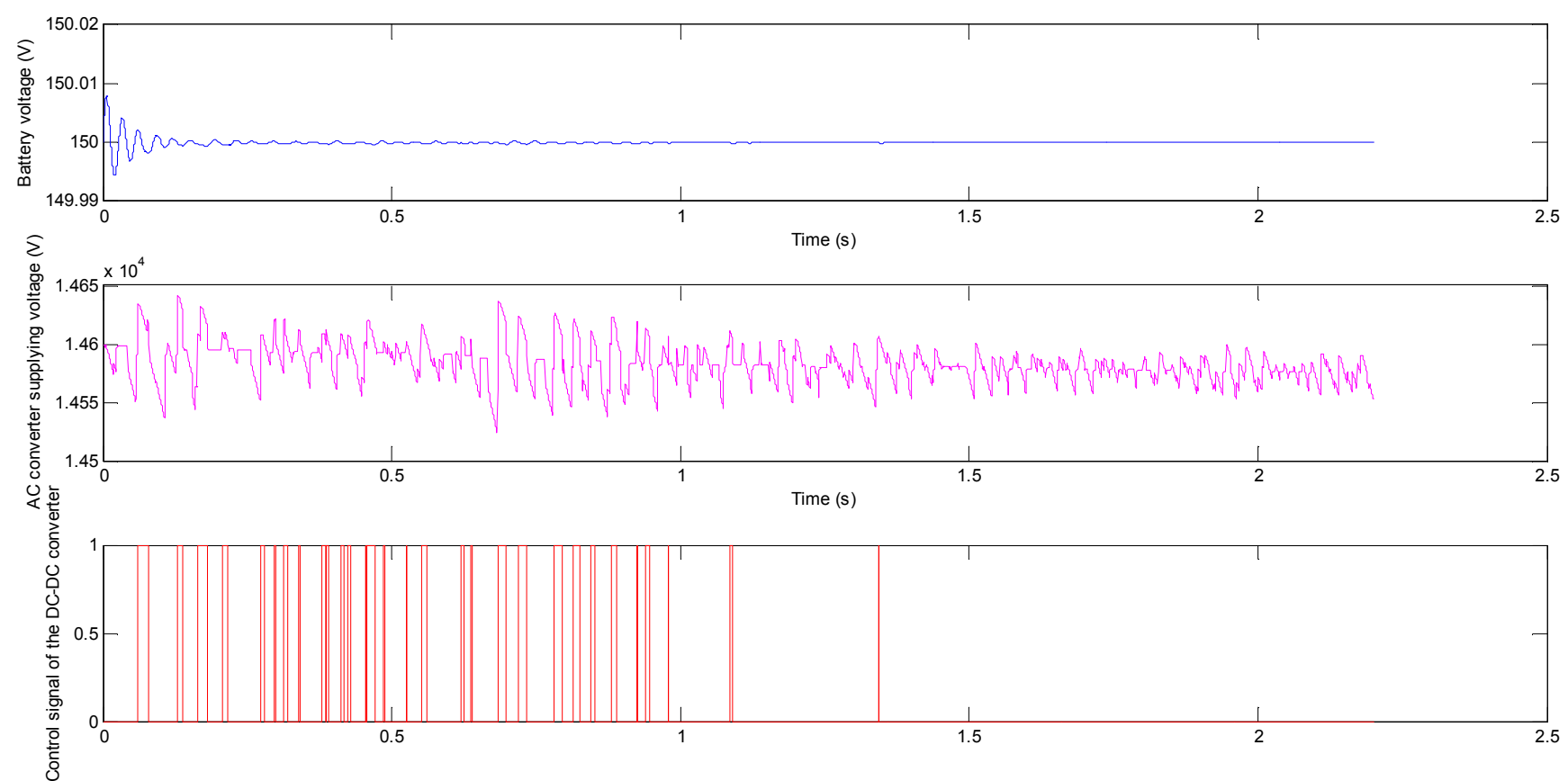

Figure 13. Battery voltage and the DC bus elevated volatge.

Figure 13. Show that the DC-DC elevator convetter permit a good regulation with small fluctutations of the DC bus 
voltage supplying the $\mathrm{AC}$ converter.

The speed, the displacement of the movable stem and the two control signals are illustrated in Figure 14. This figure shows that the S1 and S2 control signals are at 1 when the movable stem position is respectively greater than $0.001 \mathrm{~m}$ and less than or equal to zero. This figure shows that changes in the position and speed of the moving stem is stabilized after two seconds, which shows the importance of dampers. Figure 14 shows that the switching frequency of the movable stem can be acheive $30 \mathrm{~Hz}$.
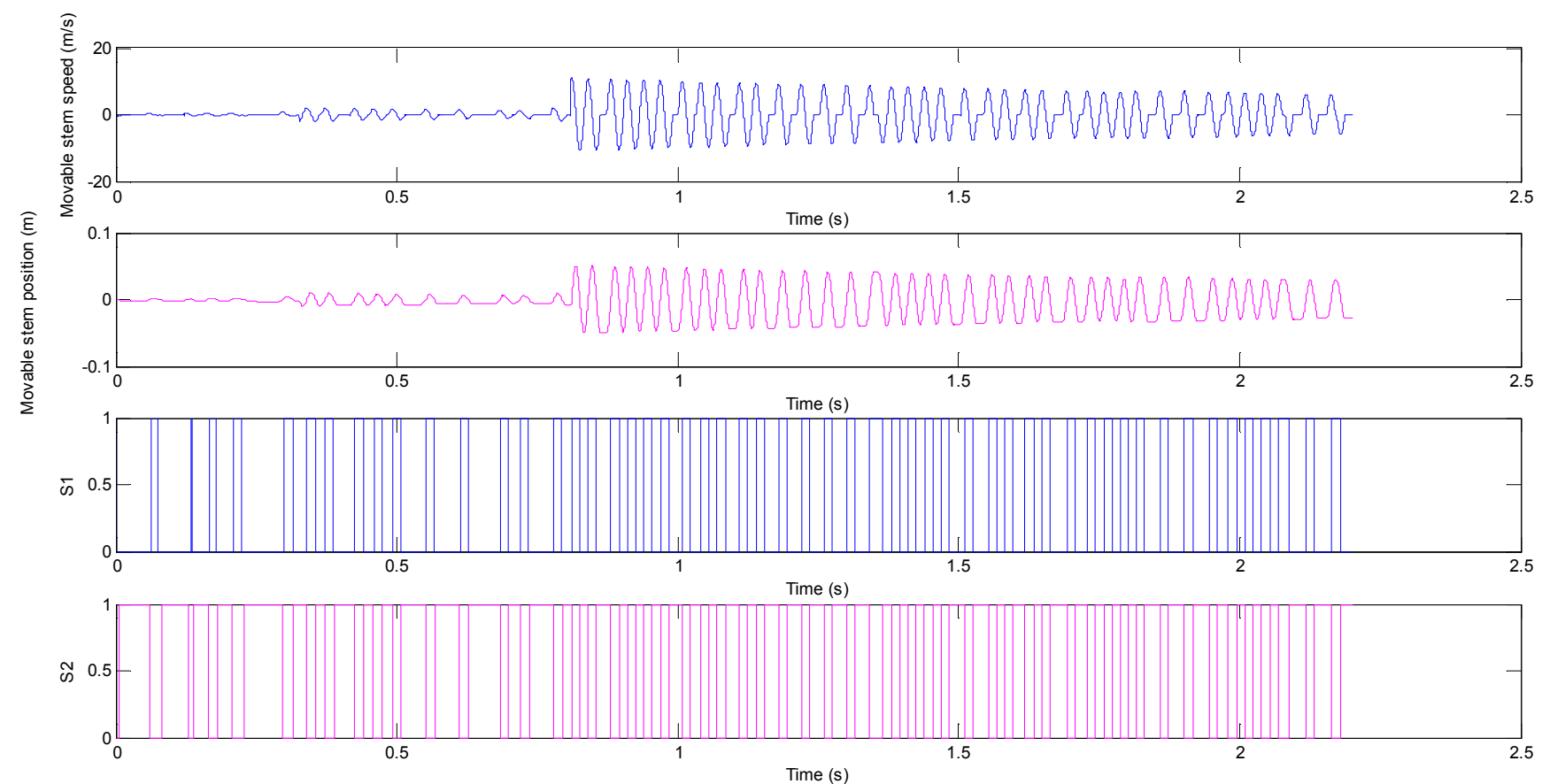

Figure 14. Evolutions over time of the movable stem speed and position and the control signals of an arm.

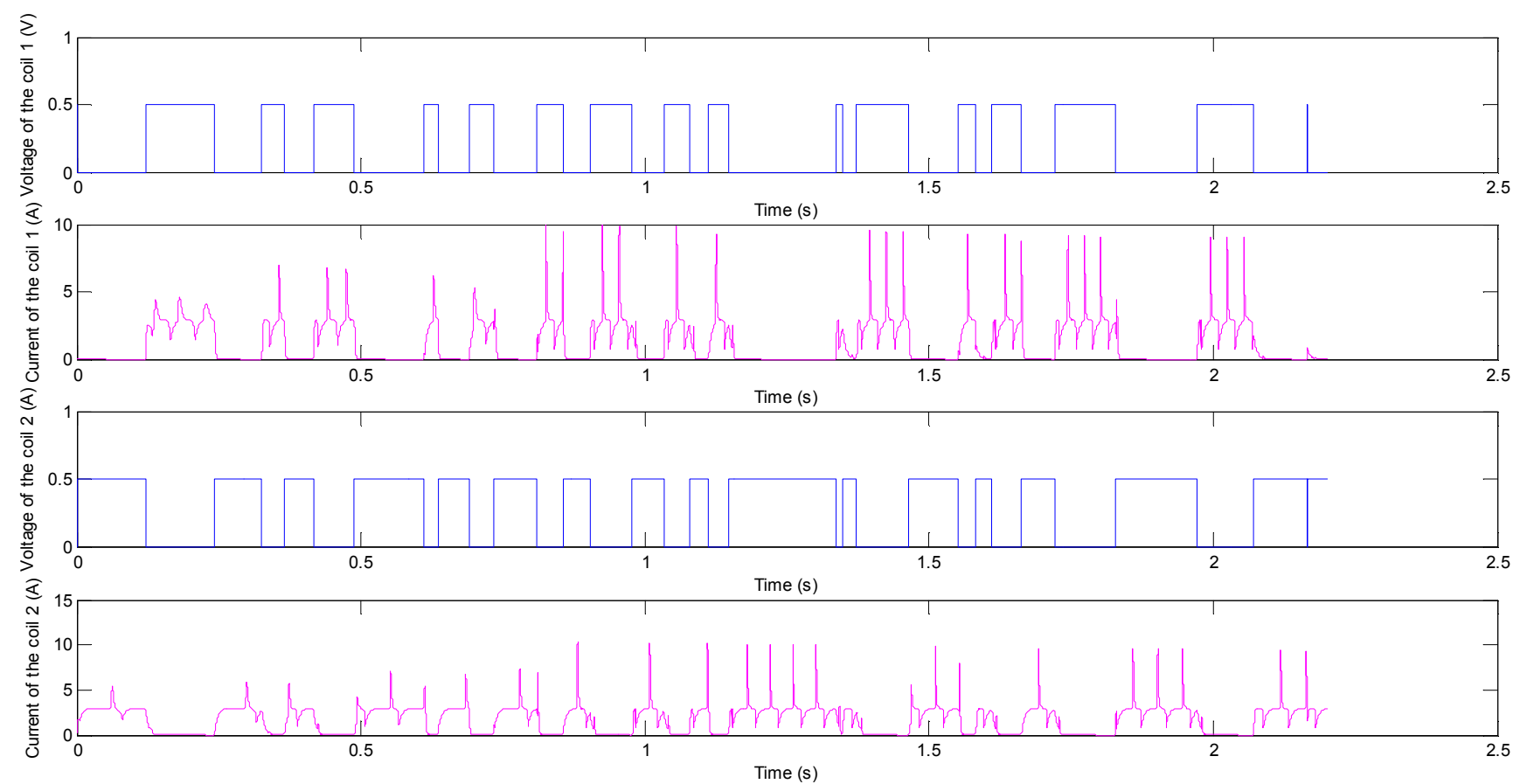

Figure 15. Evolution over time of the supply voltages and currents of the two electromagnets controlling an arm of the converter.

Figure 15 shows the evolution over time of the supply voltages and currents of the two electromagnets controlling an arm of the converter. This figure shows that there are time intervals wherein both electromagnets work together. In these cases the developed strength of the movable stem is the sum of the two strengths of the two electromagnets.

The six control signals of the electromagnetic converter are illustrated in Figure 16. This figure shows that the signals 
from each arm are complementary. This figure shows that the values of the parameters the speed and phase currents regulators are well suited as the parameter of the electromagnetic converter to achieve a switching frequency equal to $30 \mathrm{~Hz}$ Approximately.
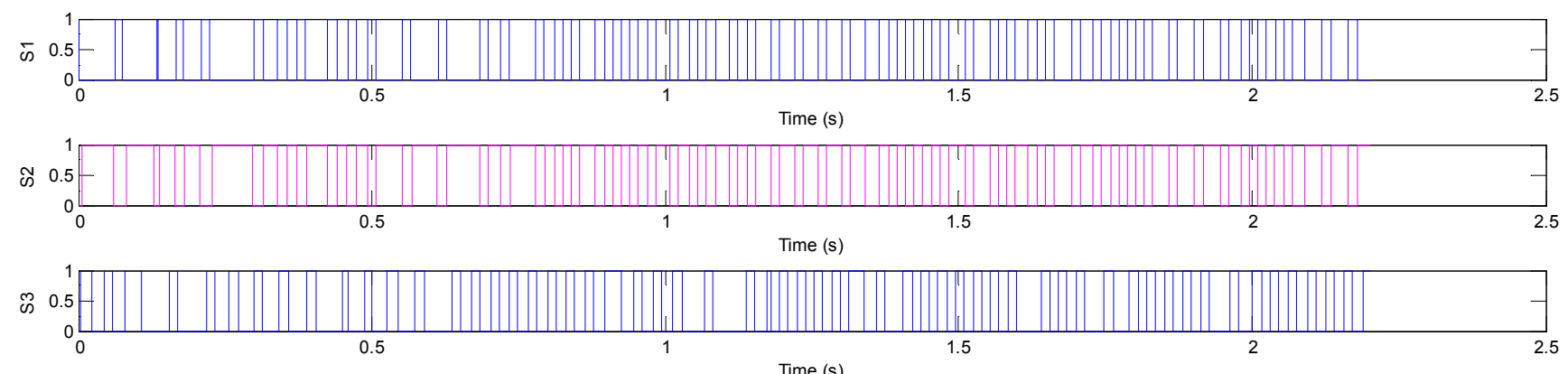

Time (s)
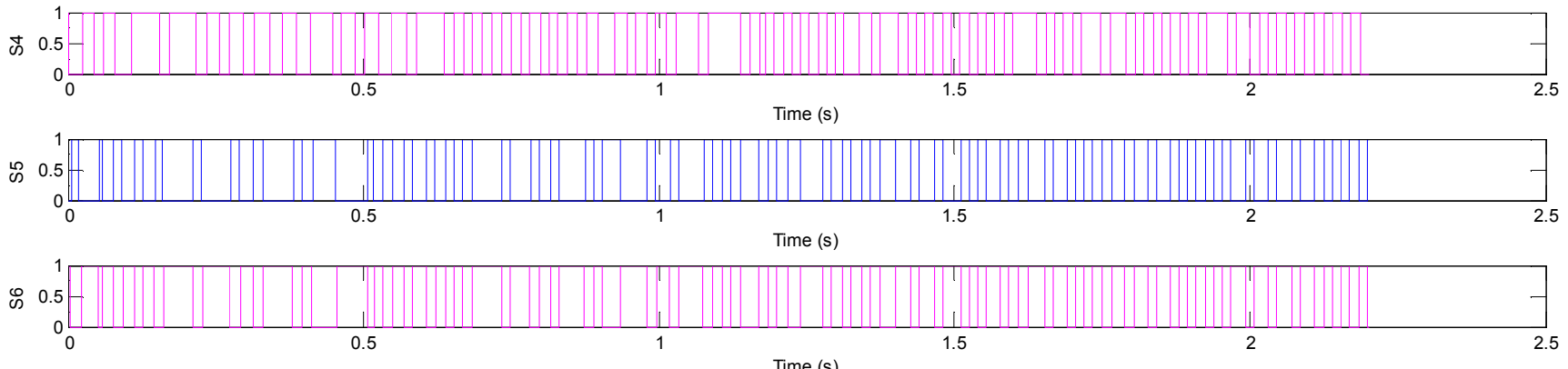

Figure 16. Control signals of the electromagnetic converter.
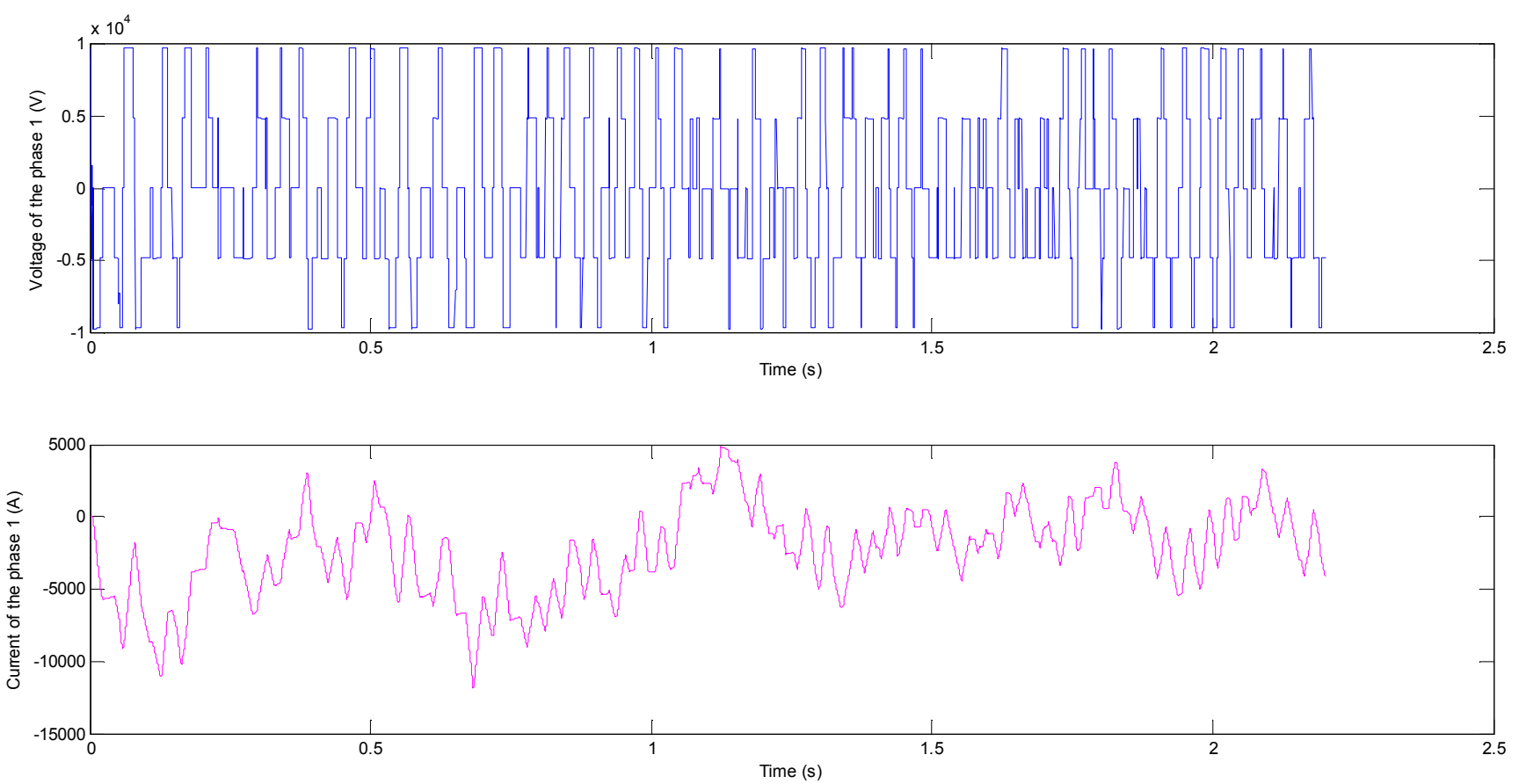

Figure 17. Voltage and current of the phase 1 evolutions over time.

Figure 17 shows changes in the voltage and current of phase 1. This figure shows the great value of the phase voltage. This important value cause a problem solved by interfacing a boost converter between the DC voltage source and the electromagnetic converter. This figure also shows the presence of harmonics of order greater than one which can be reduced by optimizing the parameters of electromagnets and design and control parameters of the power chain.

The Figure 18 illustrates the evolutions over time of the back electromotive force and the current of the Phase 1 . The control algorithm imposes backs electromotive forces in phase with current in order to reduce consumption. Figure 18 shows that this property is not actually reached next to the dynamics of the electromagnetic converter. 

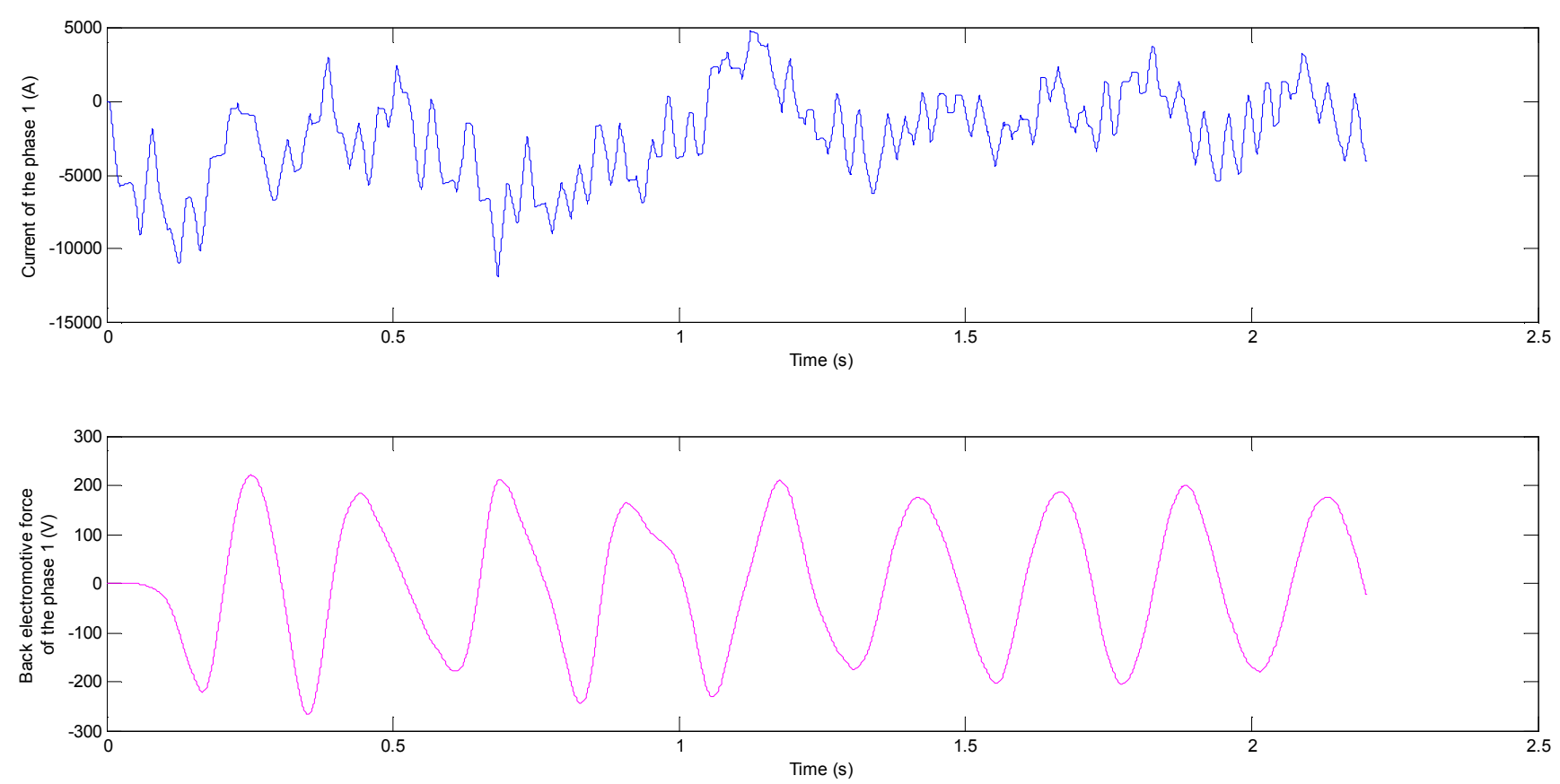

Figure 18. Back electromotive and current of the phase 1 evolutions over time.

The three phase currents evolutions over time are illustrated in Figure 19. This Figure shows the existence of harmonic with order higher then one. The no sinusoidal forms of the phase's currents is caused by the dynamic of electromagnetic switches.
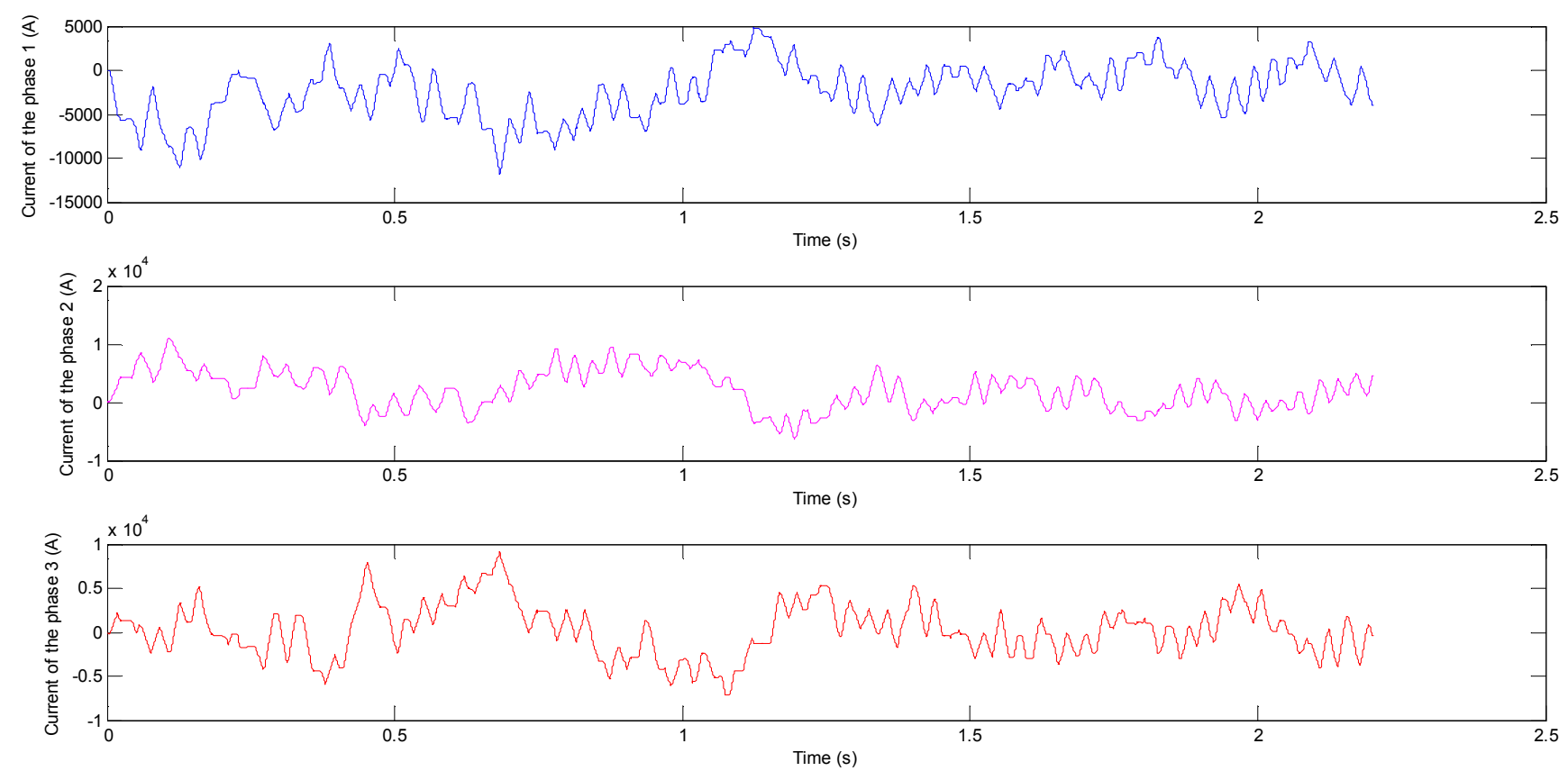

Figure 19. Evolutions over time of the three phase's currents.

The evolution of the electromagnetic torque over time is illustrated in Figure 20. This figure shows the fluctuations of the electromagnetic torque between positive values and other negative which is explained by the poor dynamics of the electromagnetic converter. 


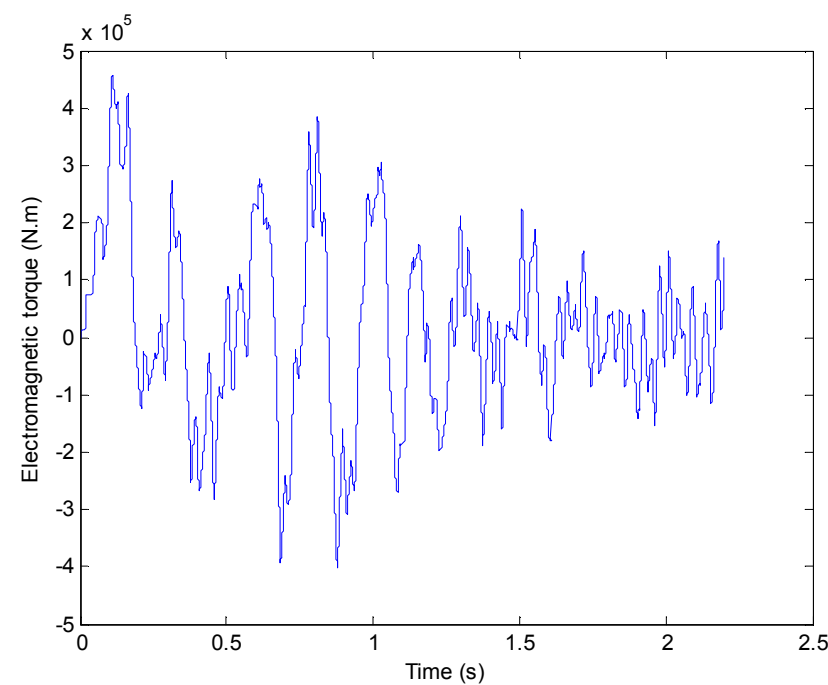

Figure 20. Evolution over time of the motor electromagnetic torque.

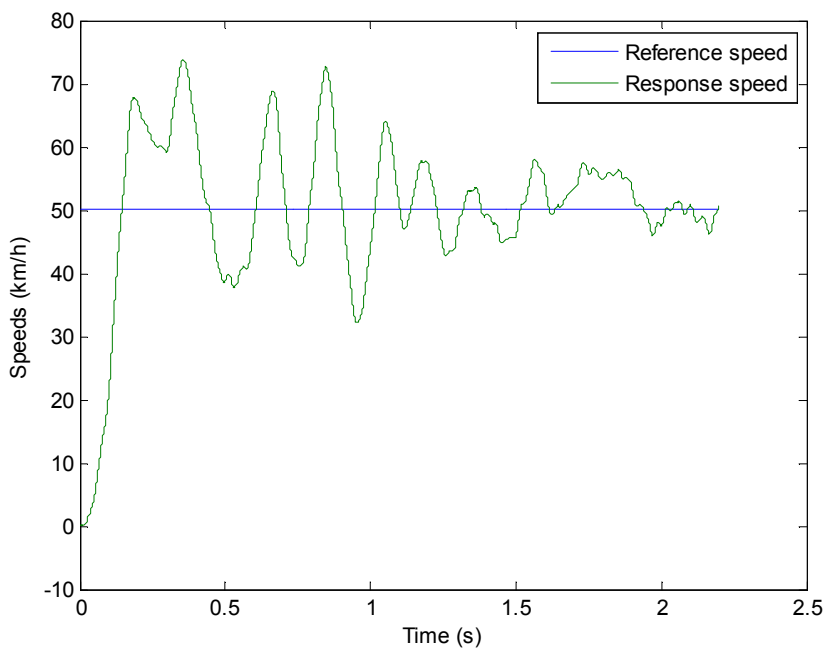

Figure 21. Evolutions over time of vehicle reference speed and response speed.

Changes in the reference and the response speeds are shown in Figure 21. This figure shows the existence of fluctuations in the response speed, which can be explained by the poor dynamics of the electromagnetic converter.

The simulation results show the importance of this innovative study and open the avenue of research to the work of power chain parameters optimization to improve the dynamics of the electric car equipped by the innovated structure of electromagnetic converter.

\section{Conclusion}

In this paper is presented a parameterized modelling approach of an electromagnetic converter based on a design program. The performance of this converter is analyzed by coupling the model developed to a model of an electric vehicle. Simulation results show the interest of this study and open the avenue of research to performances optimization work of this type of converter. The characteristic can be improved by optimization of the parameters of the electromagnetic converter influencing the stability of the closed and open states of the switches.

\section{References}

[1] Ajmia BEGACEM, Mohamed Amine FAKHFAKH and Souhir TOUNSI: OPTIMAL DESIGN AND CONTROL OF ELECTRIC VEHICLE POWER CHAIN. Journal of Electrical Engineering (JEE), Edition 2, juin 2015, Indexed in SCOPUS.

[2] S. TOUNSI: Losses of the electromagnetic modeling and IGBT converters. Int. J. Electric and Hybrid Vehicles (IJEHV), Vol. 5, No. 1, 2013, pp: 54-68.

[3] S. TOUNSI, M. Hadj Kacem and R. NEJI: Design of Static Converter for Electric Traction. International Review on Modelling and Similations (IREMOS), Volume 3, N. 6, December 2010, pp. 1189-1195, Indexed in SCOPUS.

[4] S. TOUNSI and R. NEJI: Design of an Axial Flux Brushless DC Motor with Concentrated Winding for Electric Vehicles. Journal of Electrical Engineering (JEE), Volume 10, 2010 Edition: 2, pp. 134-146.

[5] Aicha Khlissa, Houcine Marouani, Souhir Tounsi: Systemic Design and Modelling of a Coiled Rotor Synchronous Motor Dedicated to Electric Traction, American Journal of Electrical Power and Energy Systems. Special Issue:Design, Optimization and Control of Electric Vehicles: (DOCEV). Vol. 4, No. 2-1, 2015, pp. 1-7. doi: 10.11648/j.epes.s.2015040201.11.

[6] Aicha Khlissa, Houcine Marouani, Souhir Tounsi: Trapezoidal Control of a Coiled Synchronous Motor Optimizing Electric Vehicle Consumption, American Journal of Electrical Power and Energy Systems. Special Issue:Design, Optimization and Control of Electric Vehicles: (DOCEV). Vol. 4, No. 2-1, 2015, pp. 17-25. doi: 10.11648/j.epes.s.2015040201.13.

[7] Moez Hadj Kacem, Souhir Tounsi, Rafik Neji: Determination of the Parameters of the Synchronous Motor with Dual Excitation. American Journal of Electrical Power and Energy Systems. Special Issue:Design, Optimization and Control of Electric Vehicles: (DOCEV). Vol. 4, No. 2-1, 2015, pp. 26-32. doi: 10.11648/j.epes.s.2015040201.14.

[8] Souhir Tounsi: Modelling and Control of Electric Vehicle Power Train. American Journal of Electrical Power and Energy Systems. Special Issue:Design, Optimization and Control of Electric Vehicles: (DOCEV). Vol. 4, No. 2-1, 2015, pp. 33-41. doi: 10.11648/j.epes.s.2015040201.15.

[9] Mariem Ben Amor, Souhir Tounsi, Mohamed Salim Bouhlel: Design and Optimization of Axial Flux Brushless DC Motor Dedicated to Electric Traction. American Journal of Electrical Power and Energy Systems. Special Issue:Design, Optimization and Control of Electric Vehicles: (DOCEV). Vol. 4 No. 2-1, 2015, pp. 42-48. doi: 10.11648/j.epes.s.2015040201.16.

[10] Souhir Tounsi: Systemic Design and Optimization Improving Performances of Permanent Magnet Motors. International Journal of Electrical Components and Energy Conversion. Vol. 1, No. 1, 2015, pp. 1-15. Doi: 10.11648/j.ijecec.20150101.11. 
[11] Ajmia Belgacem, Mariem Ben Amor, Souhir Tounsi: Trapezoidal Control Based on Analytical and Finite Element Identification of Axial Flux Brushless DC Motor Dedicated to Electric Traction. International Journal of Electrical Components and Energy Conversion. Vol. 1, No. 1, 2015, pp. 16-23. doi: 10.11648/j.ijecec.20150101.12.

[12] Mariem Ben Amor, Ajmia Belgacem, Souhir Tounsi: Optimal Design and Control of Electric Vehicles Power Chain with Electromagnetic Switch. International Journal of Electrical Components and Energy Conversion. Vol. 1, No. 1, 2015, pp. 24-35. doi: 10.11648/j.ijecec.20150101.13.

[13] Moez Hadj Kacem, Souhir Tounsi, Rafik Neji: Losses Modeling of the Electric Vehicles Power Chain. International Journal of Electrical Components and Energy Conversion. Vol. 1, No. 2, 2015, pp. 49-54. doi: 10.11648/j.ijecec.20150102.11.

[14] Zaineb Gorbel, Yamina Chihaoui, Nader Barg, Mounir Yahyaoui, Souhir Tounsi. Modelling Approach of Electric Cars Autonomy. International Journal of Electrical Components and Energy Conversion. Vol. 1, No. 2, 2015, pp. 55-62. doi: 10.11648/j.ijecec.20150102.12.

[15] Houcine MAROUANI and Souhir TOUNSI: Design of a Coiled Rotor Synchronous Motor Dedicated to Electric Traction. Journal of Electrical Systems (JES), Volume 10, Issue 3, (September 2014), Indexed in SCOPUS.

[16] S.A. RANDI, S. ASTIER, B. SARENTI: Full Modeling Approach of Electric Vehicle for Design Optimisation. EVS 18 Berlin, 2001.
[17] C. C. Chan and K. T. Chau,: An Overview of Power Electronics in Electric Vehicles. IEEE Trans. On Industrial Electronics, Vol. 44, № 1, February 1997, pp.3-13.

[18] S. TOUNSI, R. NEJI, N. BEN HADJ, F. SELLAMI: Global optimisation of electric vehicle design parameters. The 21 st worldwide battery, hybrid and fuel cell electric vehicle symposium and exhibition; EVS 21 MONACO 2-6 April 2005; CD FFP 312

[19] S. TOUNSI, R. NEJI and F. SELLAMI: Mathematical model of the electric vehicle autonomy. ICEM2006 (16th International Conference on Electrical Machines), 2-5 September 2006 Chania-Greece, CD: PTM4-1.

[20] S. TOUNSI and R. NEJI: Design of an Axial Flux Brushless DC Motor with Concentrated Winding for Electric Vehicles. Journal of Electrical Engineering (JEE), Volume 10, 2010 Edition: 2, pp. 134-146.

[21] D-H. CHO, J-K. KIM, H-K. JUNG and C-G. LEE: Optimal design of permanent-magnet motor using autotuning Niching Genetic Algorithm. IEEE Transactions on Magnetics, Vol. 39, No. 3, May 2003.

[22] S. LEE, K. KIM, S. CHO, J. JANG, T. LEE and J. HONG: Optimal design of interior permanent magnet synchronous motor considering the manufacturing tolerances using Taguchi robust design. Electric Power Applications, IET, vol 8 no 1, 23-28, 2014. 